\title{
RESEARCH ON THE EFFECTIVENESS OF TEACHING BIOSTATISTICS OF FUTURE PHYSICIANS
}

10.36740/WLek202010123

\author{
Tetiana S. Gruzieva ${ }^{1,2}$, Nataliia V. Stuchynska ${ }^{1}$, Hanna V. Inshakova ${ }^{1,2}$ \\ 'BOGOMOLETS NATIONAL MEDICAL UNIVERSITY, KYIV, UKRAINE \\ 2STATE INSTITUTION OF SCIENCE «RESEARCH AND PRACTICAL CENTER OF PREVENTIVE AND CLINICAL MEDICINE» STATE ADMINISTRATIVE \\ DEPARTMENT, KYIV, UKRAINE
}

\begin{abstract}
The aim: To evaluate the effectiveness of teaching biostatistics of future physicians in the context of the introduction of a new curriculum on the subject «Social Medicine, Public Health» in the «Biostatistics» module.

Materials and methods: During the study 2 groups of students that had different curriculum were formed - experimental group (EG) ( $\mathrm{n}=257)$ and control group (CG) ( $\mathrm{n}=$ 272). Their level of knowledge, skills and abilities was determined with the help of a sociological survey. The level of acquired competencies of students was assessed according to the developed motivational, cognitive, activity and reflective criteria. Bibliosemantic, analytical, sociological, medical-statistical and experimental methods were used to analyze the results.

Results: The study analyzed and identified differences in a number of indicators related to the combination of work and study (EG $-28.4 \pm 2.8,(\mathrm{CG}-43.3 \pm 3.0$ per 100 students), preferences for the study of biostatistics ( $E G)-47.2 \pm 3.1,(G-30.5 \pm 2.8$ per 100$)$, acquaintances with statistical sizes and methods before the beginning of training of biostatistics ( $E G-32.9 \pm 3.0, C G-41.1 \pm 3.0$ per 100$)$, the presence of difficulties in mastering the subject $(E G-50.2 \pm 3.1,(G-53.2 \pm 3.0$ per 100$)$. The reasons for dissatisfaction with the educational process, the optimal forms and methods of teaching biostatistics were identified. The proposals of students to improve the quality of teaching the subject are studied. The plans of the participants of the experiment for further study of biostatistics and its use in future professional activities have been clarified.

Conclusions: The data obtained indicate that the implementation of the new curriculum «Social Medicine, Public Health» in the module «Biostatistics» has had a positive impact on improving the professional competence of students in biostatistics, which proves its effectiveness.
\end{abstract}

KEY WORDS: Biostatistics; educational programs; subject competences; criteria of knowledge formation; efficiency of implementation

Wiad Lek. 2020;73(10):2227-222

\section{INTRODUCTION}

The widespread adoption of evidence-based medicine, digital technologies, the active use of mathematical apparatus in the medical field, etc., increase the requirements for the professional competence of specialists in this field. In such circumstances, the issue of qualitative training of future specialists of medical profile in higher education institutions is urgent, which in turn requires the development of new educational programs or modernization of existing ones.

New quality education programs should create a reliable basis for European and world integration, enhance the reputation of Ukrainian higher educational institutions, particularly medical, both on the national and international levels [1].

An important aspect of the implementation of new educational programs is the monitoring of their effectiveness, a comparative analysis of the acquired competences of students who received knowledge in the same academic discipline, but under different programs. In 2018/2019 a new educational program in the discipline «Social Medicine, Public Health» of training of masters of medicine has been introduced. The program developed by the specialists of the Department of Social Medicine and Public Health of the Bogomolets National Medical University (NMU) [2]. The first year of study involves mastering the "Biostatistics» module.

Biostatistics is a powerful tool for the development of research questions, research design, measurement refinement, data analysis and interpretation of findings [3-6]. It is an important component of empirical research in both public health and clinical medicine. The best studies have a biostatistical contribution, starting with the design of the study and ending with the analysis and presentation of the data. Medical statistical methods are the basis for key health science research disciplines such as epidemiology and health care research [7-9].

Many scholars have emphasized that quite often in published articles, even in high impact factor journals, one misuses statistical methods. This is most often due to improper use of tests, presentation of data analyzed by nonparametric methods, as averages, analysis of independent sets as dependent, etc. [10-11].

Researchers call the lack of biostatistical knowledge the main cause of such difficulties, which in turn requires better 
training of health care professionals at all levels of education in higher education institutions $[7,12,13]$. Due to the need to analyze large data sets, causal relationships, the emergence of precision medicine, artificial intelligence, etc., modern statistical methods are developed, the knowledge of which is obligatory for biostatistics specialists. All this requires the development of qualitatively new educational programs and improvement of existing ones in the discipline «Biostatistics» $[14,15]$. Such programs should be aimed at interdisciplinary integration, a combination of educational and scientific activities, widespread use of digital technologies, in particular, information and communication $[12,16]$.

\section{THE AIM}

To evaluate the effectiveness of teaching biostatistics of future physicians in the context of the introduction of a new curriculum on the subject «Social Medicine, Public Health» in the «Biostatistics» module.

\section{MATERIALS AND METHODS}

The sources of information became the results of a sociological survey on study the acquired competencies of students in the basics of biostatistics, as well as assessment of the level of knowledge of students on the basis of motivational, active and reflexive criteria developed by specialists of the Department of Social Medicine and Public Health of the NMU.

The sociological survey was conducted among students of $3^{\text {rd }}$ and $4^{\text {th }}$ years of the NMU, where the module "Biostatistics» was studied. A pedagogical experiment was applied during the research and experimental work. The sample size was 272 students of $4^{\text {th }}$ year who enrolled in 2014/2015 - 2015/2016 according to the typical program of the discipline «Biostatistics» of training specialists of educational and qualification level «specialist» for students of the Higher education institutions of Ministry of Public Health of Ukraine (2014) and constituted the CG, and 257 students of the $3^{\text {rd }}$ year of 2018/2019 who have mastered the subject in accordance with the new program in the discipline «Social Medicine, Public Health» of training masters of medicine (2018) and related to the EG.

An appropriate toolkit was developed for the survey, which consisted of an anonymous questionnaire, which included 24 questions in several blocks, namely: general information about the respondent, sources of knowledge about statistical methods and areas, the expediency of their use, respondents' opinion on more acceptable form of study and more effective way of studying biostatistics, reasons for dissatisfaction with the educational process, and recommendations for improving the quality of teaching biostatistics.

Bibliosemantic, analytical, sociological, medico-statistical and experimental methods were applied during the study.

\section{RESULTS}

From 2018/2019 a new educational program in the discipline «Social Medicine, Public Health» of training masters of medicine was introduced into the educational process of institutions of higher medical education of Ukraine. The program is structured in four modules, the first of which is «Biostatistics». The module consists of 3 credits, 20 hours of which are allocated for lectures, 30 hours for practical classes and 40 hours of independent student work. The topics of the practical classes were also expanded, and the topics that were assigned to self-study began to be covered in the classroom practical classes.

One of the first questions posed to the respondents was the important question of combining work with study, as the sufficient time spent on study as a whole and, in particular, biostatistics, depends on it. The results of the study showed that $43.3 \pm 3.0$ per 100 CG students were employed, while in EG this indicator was lower by $34.4 \%$ and amounted to $28.4 \pm 2.8$ per 100 respondents.

Biostatistics was noted as interesting and enjoyable by only a third of CG students $-30.5 \pm 2.8$ per 100 respondents and almost half $-47.2 \pm 3.1$ per 100 respondents - EG students, which is by $54.8 \%$ more than in CG. Tired by the end of biostatistics sessions, $49.4 \pm 3.0$ per 100 CG respondents and $34.8 \pm 3.0$ per $100 \mathrm{EG}$ respondents.

The effectiveness of propaedeutical preparation for the discipline was studied in detail: familiarization with statistical values and methods, as well as the sources of obtaining such knowledge. The analysis of the answers showed that $41.1 \pm 3.0$ per 100 respondents had such knowledge in CG, and in EG this indicator was lower by $20.0 \%$ and amounted to $32.9 \pm 2.9$ per 100 respondents. Among the various sources of awareness of statistical methods, the first places in both the CG and the EG were the knowledge gained in previous courses, namely, medical physics and informatics, from the school; Internet; the professor; when performing scientific work, etc.

Biostatistics is a difficult discipline to master. This is recognized by the students and confirmed by the experiment. Both students of $4^{\text {th }}$ year (CG) and students of $3^{\text {rd }}$ year (EG) had difficulties in studying biostatistics. But, nevertheless, among the $3^{\text {rd }}$ year students this indicator is lower than in EG by $5.6 \%$ and is $50.2 \pm 3.1$ per 100 respondents, while in CG it is $53.2 \pm 3.0$ per 100 respondents. At the same time, the rate of mastering the subject without problems is higher in the EG by $8.9 \%(34.2 \pm 3.0$ in the EG and $31.4 \pm 2.8$ in the CG) (Fig. 1).

One of the important questions of the sociological survey on acquired competences in biostatistics was to study the reasons for dissatisfaction with the educational process in its mastering. The first two places among these reasons misunderstanding of the essence of mathematical formulas and lack of time for mastering the topic, coincided in both groups - EG (47.2 \pm 3.1 per 100 respondents and 34.1 \pm 3.0 , respectively) and CG (47.2 \pm 3.0 and 33.6 \pm 2.9 , respectively). Due to the introduction of a new educational program, EG students called the fast pace of classes as one of the reasons less by $35.5 \%$ (21.4 \pm 2.6 per 100 students) than CG students (33.2 \pm 2.9 ), lack of examples of application of biostatistics in practice and connection with the future activity - by $33.6 \%(19.2 \pm 2.5$ and $28.9 \pm 2.7$ per 100 respondents, respectively), lack of didactic materials on the 


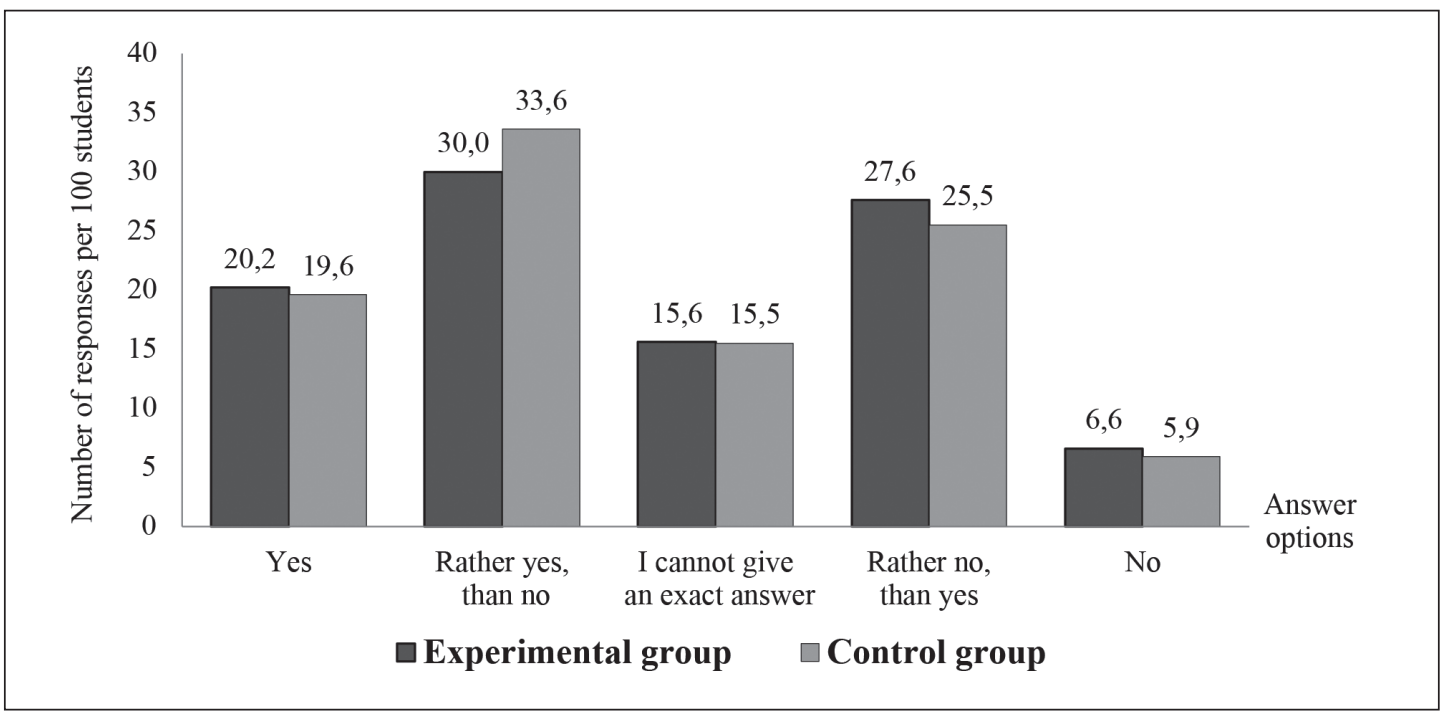

Fig. 1. Survey results of the students of $\mathrm{EG}$ and $\mathrm{G}$ about the difficulties while mastering biostatistics (per 100 respondents).

Table I. Opinion of medical students on more acceptable forms and methods of teaching biostatistics (per 100 respondents)

\begin{tabular}{|c|c|c|}
\hline Indicators & $\begin{array}{c}\text { EG } \\
\text { (per } 100 \pm m)\end{array}$ & $\begin{array}{c}\text { CG } \\
(\text { per } 100 \pm m)\end{array}$ \\
\hline \multicolumn{3}{|c|}{ Forms of study: } \\
\hline teaching under the guidance of a teacher & $66.3 \pm 2.9$ & $62.1 \pm 2.9$ \\
\hline observing the problems solution during the class & $30.6 \pm 2.9$ & $31.6 \pm 2.8$ \\
\hline solving problems with another student & $7.9 \pm 1.7$ & $11.9 \pm 2.0$ \\
\hline independent problem solving with the help of didactic materials & $8.3 \pm 1.7$ & $8.6 \pm 1.7$ \\
\hline \multicolumn{3}{|c|}{ Learning methods: } \\
\hline professionally oriented tasks & $69.2 \pm 2.9$ & $75.1 \pm 2.6$ \\
\hline providing answers to typical test tasks & $15.8 \pm 2.3$ & $17.5 \pm 2.3$ \\
\hline performing creative tasks & $19.0 \pm 2.4$ & $12.3 \pm 2.0$ \\
\hline solving complex non-standard tasks & $13.0 \pm 2.1$ & $9.3 \pm 1.8$ \\
\hline
\end{tabular}

subject - by $28.3 \%(11.9 \pm 2.1$ and $16.6 \pm 2.3$, respectively), a large amount of material for mastering - by $24.6 \%$ $(21.8 \pm 2.6$ and $28.9 \pm 2.7$, respectively). With regards to the basic mathematical knowledge obtained at school as one of the reasons for difficulties in mastering biostatistics, this indicator was $27.2 \%$ higher for EG students than for CG students (33.2 \pm 2.9 and $26.1 \pm 2.5$ per 100 respondents, respectively).

The task of research was to study students' opinions on the best forms and most effective ways of teaching biostatistics. The results of the study are given in table I.

The study provided an analysis of students' suggestions regarding improvement of the quality of teaching biostatistics. Most students expressed a desire of demonstration of examples of the use of biostatistics in their future professional activities during the classes. This indicator among CG students was $60.6 \pm 3.0$ per 100 respondents, while in EG it was lower by $15.3 \%$ and amounted to $51.4 \pm 3.1$. Second among students' proposals was the broader use of cross-curricular links in biostatistics to other disciplines. Thus, among future CG doctors, the frequency of positive answers was $40.7 \pm 3.0$ per 100 respondents, while among
EG students it was lower by $12.5 \%-35.6 \pm 3.0$. Students also indicated the need to include biomedical content in the educational content. This indicator among CG students was $34.0 \pm 2.9$, and in the EG group it was lower by $23.8 \%$ and amounted to $25.9 \pm 2.7$ per 100 respondents. Regarding the students' opinion on improving the efficiency and quality of teaching the subject, the leading places among the proposals were in the following groups: to issue teaching materials with formulas and examples (EG $-8.9 \pm 1.8$, CG $-10.7 \pm 1.9$ per 100 respondents); to increase the number of hours for biostatistics mastering $(6.5 \pm 1.5$ and $7.9 \pm 1.6$ per 100 respondents, respectively); to explain the topic more in detail during the classes $(5.3 \pm 1.4$ and $6.1 \pm 1.5$ per 100 respondents, respectively).

The last block of questions concerned the future plans of future physicians in mastering biostatistics and the need to use the acquired knowledge in medical work and scientific activity. The fact that half of the students of the EG $-50.2 \pm 3.1$ per 100 respondents - considered it advisable to continue studying the subject, is encouraging, which was $64.6 \%$ more than in the CG $-30.5 \pm 2.8$. Moreover, the relationship between CG was observed between the 


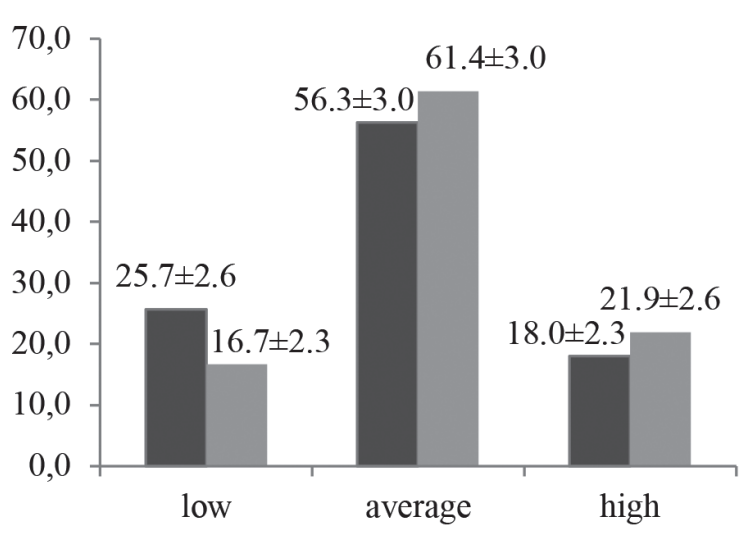

motivational

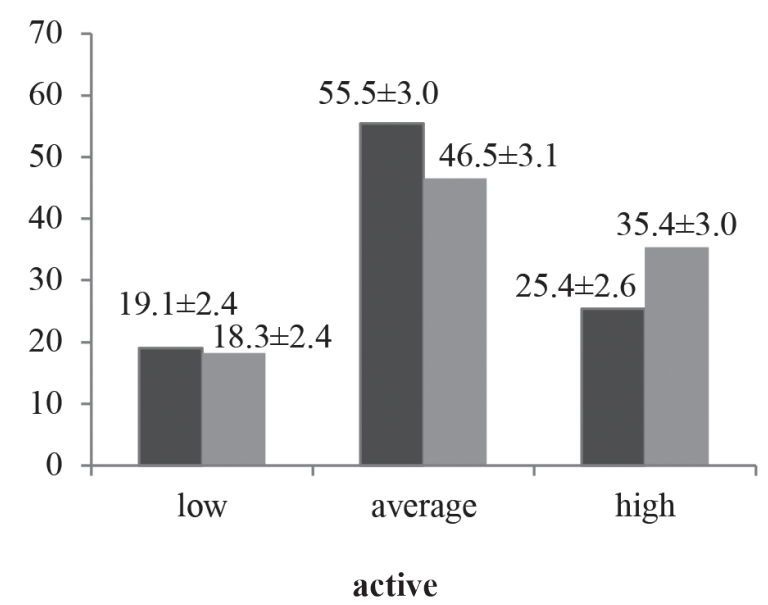

Control group

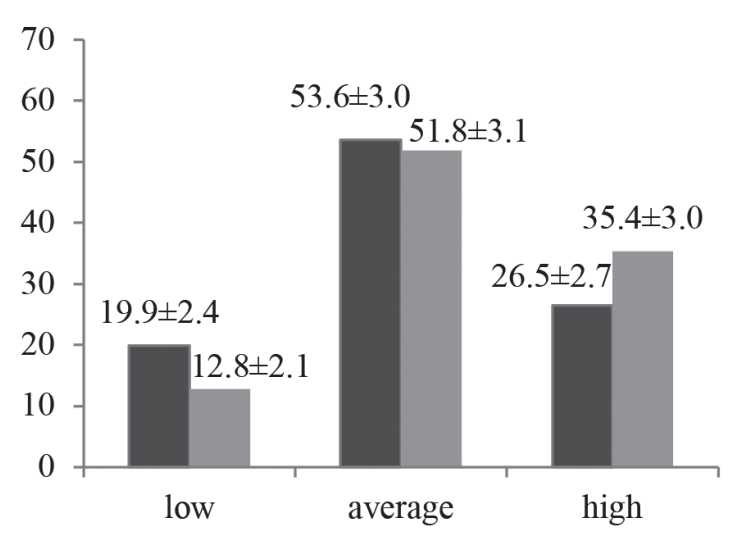

cognitive

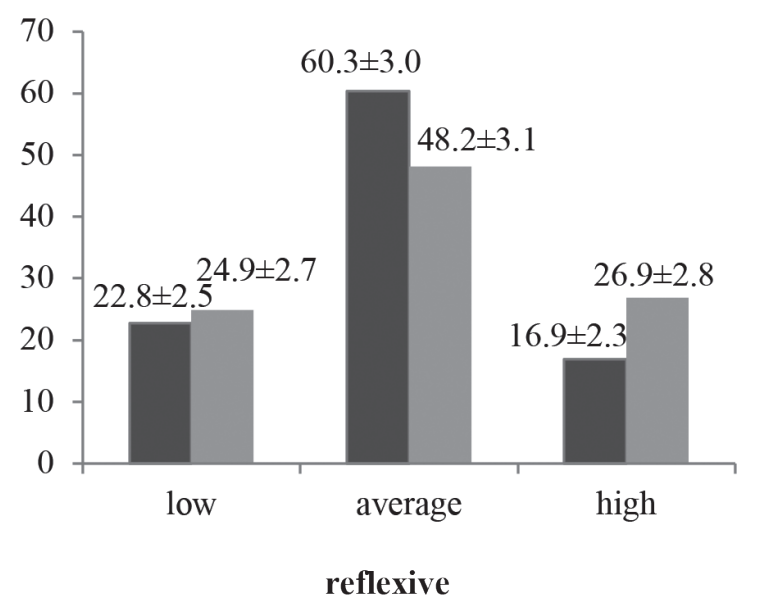

Experimental group

Fig. 2. Levels of professional competence formation on the basics of biostatistics according to the relevant criteria among students of CG and EG (per 100 students).

expediency of continuing the study of biostatistics and difficulties in its mastering $\left(\chi^{2}=24,2, p<0,001\right)$, while no such dependence was detected in $\mathrm{EG}\left(\chi^{2}=2,5, \mathrm{p}>0,05\right)$. Examination of students' opinion on the need for biostatistical knowledge in practical and scientific activities showed that the need for such knowledge was confirmed by $72.4 \pm 1.7$ per 100 medical students of CG, 68.3 $\pm 2.9-\mathrm{EG}$, which is lower by $5,7 \%$. This is explained by the fact that under the previous program, students have mastered biostatistics in the $4^{\text {th }}$ year, where they are already more actively engaged in scientific work and apply biostatistical indicators, as well as encountering practical activities in the field of health care. In developing this question, students were asked about the reasons for the need to study biostatistics. The analysis of the results showed the following: 49.2 \pm 3.1 per $100 \mathrm{EG}$ respondents and 53.4 \pm 3.0 - CG considered that it might be necessary for further use in the future profession; for general development $-44.0 \pm 3.1$ and $45.5 \pm 3.0$; for the study of other disciplines $-9.1 \pm 1.8$ and $3.0 \pm 1.0$, respectively.

To determine the level of acquired competences in biostatistics among medical students at the Department of Social Medicine and Public Health of NMU, an evaluation method was developed. It envisaged assessing the level of knowledge of future physicians by motivational, cognitive, activity and reflexive criteria, their corresponding indicators and levels of knowledge formation. The motivational criterion determined the motives for students to master biostatistics, a manifestation of interest in the discipline, a desire to gain knowledge of the subject, understanding of its need in the future profession. The cognitive criterion was the set of acquired knowledge and their quality, depth, systematicity, compliance with the requirements of state educational standards. The activity criterion evaluated the formation of professional competence in the use of knowledge of biostatistics in practice, the identification of students' individual qualities. The reflexive criterion is aimed at self-development, the ability to correctly evaluate one' activities, to compare and adequately interpret one' own and external results of knowledge control in biostatistics. The levels of competence of students in biostatistics for each of the criteria were developed, namely: low, medium and high. Each of these levels is assigned a corresponding quantitative value in points: a low level - 2-4 points, an medium- 5-9 points and a high $-10-12$ points. The results 
of the evaluation by the professors of the acquired competence of medical students, who studied under different educational programs, according to the given criteria are presented in Fig. 2.

\section{DISCUSSION}

Although all students recognize that biostatistics is a difficult discipline to master, however, if the student likes to study this subject, he/she does not get tired during the classes. There is an inverse, medium-strength relationship between interest in mastering the subject and fatigue in the classroom, which confirms Spearman's rank correlation coefficient $(\rho=-0,5 \pm 0,15, p<0,05)$. It should be noted that students who liked to study biostatistic methods mostly did not get tired in class, were interested in the subject and understood its importance. Moreover, the analysis of fatigue indices among students who studied under different educational programs, regarding the difference between these values, proved the statistical significance of the results $\left(\chi^{2}=15,0, p<0,001\right)$.

The analysis of the sources from which respondents learned about statistical methods reveals that the students of the EG acquired the knowledge of statistical methods in the study of medical physics and computer science by $37.4 \%$ more often than CG students. This is quite natural, because the study of these disciplines is a clear example of the implementation of the principles of consistency, which ensure the continuity of the content of training, consistent development and improvement of professional competence. According to the new educational program, the discipline «Medical and biological physics» is taught in the $1^{\text {st }}$ year of study. The program envisages mastering 4 content modules, the first of which - «Fundamentals of Mathematical Processing of Biomedical and Biological Data», contains topics such as elements of probability theory and mathematical statistics. Subsequently, this knowledge is integrated into the mastering of biostatistics. According to the new educational program «Medical informatics» is taught in the $2^{\text {nd }}$ year, three content modules are studied, knowledge of two of which is directly applied in the study of biostatistics. These are the content modules «Applied information technologies for the collection, saving, transmission and analysis of biomedical data. Statistical data analysis technology» and "Computer data visualization technologies in the field of biomedical research. Computer simulation technologies, decision support, and forecasting in biomedical research». Thus, it is logical that the knowledge acquired in the $1^{\text {st }}$ and $2^{\text {nd }}$ years is better stored in memory until the $3^{\text {rd }}$ year, during which the biostatistics is studied, and is the priority source of students' awareness of medical and statistical methods.

Students of both EG and CG admit that they face difficulties while studying biostatistics. Difficulties in the study of discipline, generally, are related to understanding the essence of mathematical formulas, calculations and their interpretation, as well as the practical application of biostatistic methods.
The study found that students' opinions regarding the best forms and methods of teaching biostatistics largely coincided. The positive fact is, that future physicians who have mastered biostatistics under the new educational program have preferred to perform creative assignments and solve non-standard tasks. This indicates a more serious attitude to the discipline and a deeper understanding of the discipline.

The study found that students enrolled in a new educational program were more motivated to master biostatistics. The low level of knowledge on the motivational criterion was lower than the one of the students who had mastered the subject in the previous program by $35.0 \%$, and the indicators of medium and high - higher by $9.1 \%$ and $21.7 \%$.

As a cognitive criterion, low and medium levels of EG students' knowledge were lower by $35.7 \%$ and $3.4 \%$, while high level of knowledge by $35.6 \%$ higher was demonstrated by EG students. Regarding the performance criterion for knowledge assessment, low and medium levels of knowledge were lower in the EG by $28.8 \%$ and $16.2 \%$ respectively, while at the same time, the high level of knowledge in the EG was higher to the one in the CG by $39.4 \%$. According to the reflexive criterion, the low level of knowledge was higher for the students of EG by $7.6 \%$, and the medium- lower by $20.1 \%$. This can be explained by the fact that this criterion provided the ability to adequately analyze and evaluate their activities, to compare them with the evaluation of the professor and his colleagues. In this regard, the students of the $3^{\text {rd }}$ year are less experienced than the students of the $4^{\text {th }}$ year. However, despite this, the high level of reflexive knowledge was higher by $59.2 \%$ for the EG students.

Statistical processing of the obtained results proved the dependence of students' level of knowledge on the educational programs under which they mastered biostatistics, according to each of the applied criteria. The statistical significance of the obtained results in EG and CG is confirmed by the calculated criterion of conformity (Pearson): by motivational criterion $-\chi^{2}=6.3(\mathrm{p}=0.038)$, by cognitive $-\chi^{2}=9.5(\mathrm{p}=0.024)$, by activity $-\chi^{2}=6.7(\mathrm{p}=0.036)$ and reflexive $-\chi^{2}=9.8(\mathrm{p}=0.008)$, which can be used as evidence of the effectiveness of implementation of the new educational program in the module «Biostatistics».

\section{CONCLUSIONS}

Analysis of the results showed that in the vast majority the indicators studied for the analysis of acquired competences in biostatistics during the pedagogical experiment, were better in EG. Yes, among the EG students there were more of those who liked to study biostatistics by $54.8 \%$, compared to the CG students. EG students did not get tired at the end of classes more by $16.2 \%$, the figure of understanding the subject without problem was also higher in EG by $8.9 \%$. At the same time, the awareness of statistical methods was $24.9 \%$ higher in the CG. It was found that the students' opinions regarding the best forms and methods of teaching in most cases coincided. However, EG students 
were more willing to work on creative assignments and solve non-standard tasks, which indicates a serious attitude to biostatistics and a deep understanding of it. Half of the EG students planned to continue studying biostatistics in the future, while it was only one third among CG.

Thus, the results of the study showed that the study of biostatistics in accordance with the new educational program «Social Medicine, Public Health» on module «Biostatistics» had a positive effect on improving the level of knowledge of students in this subject. The conducted statistical analysis of acquired competences in the biostatistics of medical students by motivational, cognitive, activity and reflexive criteria proves the effectiveness of studying under the new program, what can be proven by the calculated criterion of conformity $\chi^{2}$, which exceeds the table at the level of significance $\mathrm{p}<0.05$ and $\mathrm{p}<0.01$.

\section{REFERENCES}

1. Zakharchenko V.M. , Lugovy, V.I., Rashkevich Yu M. at al. Rozroblennia osvitnikh prohram. Metodychni rekomendatsii [Educational Program Development. Guidelines]. Kyiv: DP «NVTs «Priorytety». 2014; 120. (in Ukraine).

2. Gruzeva T.S., Grechyshkina N.V., Lytvynova L.0. Hromadske zdorovia (public health) yak nova spetsialnist: suchasni pidkhody do vykladannia (na prykladi Debretsenskoho universytetu, Uhorshchyna) [Public health as a new specialty: modern approaches to teaching (for example, the University of Debrecen, Hungary]. Ukraina. Zdorovia natsii. 2017; 1: 166-172. (in Ukraine).

3. Welty L.J., Carter R.E., Finkelstein D. at al. Perspective: Strategies for Developing Biostatistics Resources in an Academic Health Center. Acad Med. 2013; 88(4): 454-460.

4. Kuzenko M. S. Statystyka v medyko-byolohycheskykh yssledovanyiakh [Statistics in biomedical research]. Nauchnbi zhurnal. 2017; 7(20): 6-10. (in Russian).

5. Fengxia Ya., Mayberry R., LiY. Statistical methods and common problems in medical or biomedical science research. Int J Physiol Pathophysiol Pharmacol. 2017; 9(5): 157-163.

6. Statistics and Science. A Report of the London Workshop on the Future of the Statistical Sciences. London; 2014; 40.

7. Lee K.J., Moreno-Betancur M., Kasza J. at al. Biostatistics: a fundamental discipline at the core of modern health data science. Med J Aust. 2019; 211(10): 444-446.

8. Ahmad D. N., Ahmad Kh. N., Mohib-ul-Haq M. at al. Some applications of biostatistics to medical research. Int. J. Adv. Res. 2019; 7(2): 28-31.

9. Rodrigues C.F.S., Lima F.J.C., Barbosa F.T. Importance of using basic statistics adequately in clinical research. Rev Bras Anestesiol. 2017; 67(6): 619-625.

10. Msaouel P., Kappos Th., Tasoulis A. at al. Assessment of cognitive biases and biostatistics knowledge of medical residents : a multicenter, crosssectional questionnaire study. Med Educ Online. 2017: 19: 236-246.

11. Hanif A., Ajmal T. Statistical Errors in Medical Journals (A Critical Appraisal). Annals. 2011; 17(2): 178-182.
12. Inshakova H.V. Zmistovno-strukturna model formuvannia profesiinoi kompetentnosti maibutnikh likariv u protsesi navchannia biostatystytsi [Content-structural model of formation of professional competency of future doctors in process of biostatistics training]. Naukovi zapysky. Seriia: Problemy metodyky fizyko-matematychnoi i tekhnolohichnoi osvity. 2016; 12(3): 151-159. (in Ukraine).

13. Touchon J.C., McCoy M.W. The mismatch between current statistical practice and doctoral training in ecology. Ecosphere. 2016; 7(8): 83-93.

14. Windish D. M., Huot S. J., Green, M. L. Medicine Residents'Understanding of the Biostatistics and Results in the Medical Literature. JAMA. 2007; 298(9): 1010-1022.

15. Zhao Y., Abebe A., Qi L. at al. New Advances in Biostatistics. Journal of Probability and Statistics. 2019; 4:181-182.

16. Stuchynska N. V., Tkachenko, Yu. P. Informatsiino-kompiuterni tekhnolohii yak zasib pidvyshchennia efektyvnosti navchalnopiznavalnoi diialnosti studentiv [Information and computer technology as a means of enhancing the effectiveness of students' educational and cognitive activity]. Naukovyi chasopys Natsionalnoho pedahohichnoho universytetu imeni M.P. Drahomanova. Seriia №5. Pedahohichni nauky: realii ta perspektyvy. 2009; 20: 137-143. (in Ukraine).

The article was performed in framework of research "Public Health Service Personnel Scientific Rationale”, (2017-2019, №. of state registration 0117U002681).

\section{ORCID and contributioship:}

Tetiana S. Gruzieva: 0000-0001-9254-7561 A,B,C,D,E,F

Nataliia V. Stuchynska: 0000-0002-5583-899X D,E,F

Hanna V. Inshakova: 0000-0002-3984-8864 ${ }^{A, B, C, D, E, F}$

\section{Conflict of interest:}

The Authors declare no conflict of interest.

\section{CORRESPONDING AUTHOR \\ Tetiana S. Gruzieva}

National Bogomolets Medical University

42/43 Saksaganskogo St., 01033 Kyiv, Ukraine

tel: 380503826824

e-mail:gruzieva@ukr.net

Received: 18.05 .2020

Accepted: 31.08 .2020

A - Work concept and design, B - Data collection and analysis, C - Responsibility for statistical analysis, D-Writing the article, E-Critical review, F - Final approval of the article 